\title{
Price promotions offered by quick service restaurants in Australia: analysis from an obesity prevention perspective
}

\author{
Evelyn SY Looi ', Kathryn Backholer ${ }^{1}$, Adrian J Cameron ${ }^{1}$, Lily Grigsby-Duffy', \\ Liliana Orellana ${ }^{2}$ and Gary Sacks ${ }^{1, *}$ (i) \\ 'Global Obesity Centre (GLOBE), Institute for Health Transformation, Deakin University, 221 Burwood Highway, \\ Burwood, VIC 3125, Australia: ${ }^{2}$ Biostatistics Unit, Faculty of Health, Deakin University, Burwood, VIC, Australia
}

Submitted 16 December 2020: Final revision received 20 May 2021: Accepted 15 June 2021: First published online 21 June 2021

\begin{abstract}
Objective: To assess the price promotions offered by major quick service restaurant (QSR) chains in Australia from an obesity prevention perspective.

Design: Cross-sectional audit of ten of the largest QSR chains in Australia. We collected information regarding temporary price promotions and 'combination deals' offered by each chain over thirteen consecutive weeks in 2019-2020. We assessed the type of promotions, the magnitude of discount, and the energy content and healthiness of items promoted (based on Victorian Government criteria).

Setting: Melbourne, Australia.

Participants: Ten major QSR chains.

Results: Temporary price promotions ( $n$ 196) and combination deals ( $n 537$ on regular menus, $n 36$ on children's menus) were observed across the ten selected QSR chains. In relation to temporary price promotions, the mean magnitude of discount for main menu items ( $n 75$ ) was $41.7 \%$. The price reductions and energy content of combination deals varied substantially the by chain, the meal size and the sides/drinks selected as part of the 'deal'. When the lowest-energy options (e.g. small chips, small sugar-free drink) were included as part of each combination deal, the mean energy content was $2935 \mathrm{~kJ}$, compared to $5764 \mathrm{~kJ}$ when the highestenergy options (e.g. large fries, large sugar-sweetened drink) were included. Almost all available products were classified as unhealthy.

Conclusion: Price promotions are ubiquitous in major QSR chains in Australia and provide incentives to consume high levels of energy. The action to restrict price promotions on unhealthy foods and ensure lower-energy default items as part of combination deals should be included as part of efforts to improve population diets and address obesity in Australia.
\end{abstract}

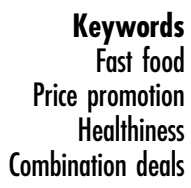

Unhealthy diets and excess body weight are leading contributors to the burden of disease in Australia and globally ${ }^{(1)}$. Australian adults and children are over-consuming discretionary (unhealthy) foods and beverages, with an average of $35 \%$ of total daily energy coming from foods and beverages that are typically high in fats, free sugars and salt ${ }^{(2)}$. In $2017-2018,25 \%$ of children and $67 \%$ of adults in Australia were classified as overweight or obese $^{(3,4)}$. Unhealthy diets and obesity have substantial health, social and economic costs, with obesity alone estimated to cost Australia $\$ 8.6$ billion each year ${ }^{(5)}$.

Meals prepared outside of the home have been increasingly identified as an important contributor to population diets $^{(6,7)}$. In Australia, over the last three decades, meals prepared outside of the home have increased from $25 \%$ to $34 \%$ of household food expenditure ${ }^{(8)}$. Fast-food restaurants (defined as 'restaurants that primarily provide consumers with largely pre-packed "quick" meals with little or no table service, and in which take-away orders are likely to account for a significant proportion of orders'(9)) represent a substantial proportion of out-of-home food purchases in Australia ${ }^{(10)}$. For example, in 2017, 44\% of the amount of money Australian households spent on eating out each week was reportedly spent in fast-food establishments ${ }^{(10)}$. In 2018, over $80 \%$ of Australians aged over 14 years reported regularly consuming fast food ${ }^{(11)}$, with adolescents identified as the highest consumers ${ }^{(7,12)}$. Fast-food meals are typically both energy-dense and nutrient-poor ${ }^{(13)}$ 
and can contribute substantially to an individual's daily energy intake ${ }^{(14)}$. A growing body of research indicates a positive association between fast-food consumption and $\mathrm{BMI}^{(15)}$ and other health outcomes, such as total cholesterol and type 2 diabetes ${ }^{(12)}$.

A range of factors has underpinned the relatively high contribution of fast food to Australian diets. These factors include high accessibility of fast-food restaurants (hereafter referred to as quick service restaurant (QSR) chains) ${ }^{(16)}$, highly pervasive and effective marketing practices of QSR chains ${ }^{(17,18)}$, and structural conditions that constrain time available for home cooking ${ }^{(3,12,19)}$. The pricing strategies of QSR chains, used in conjunction with other marketing tactics, are designed to increase sales and profitability through various means, including promoting new items, increasing frequency and size of orders, targeting and attracting different customer groups, and encouraging brand loyalty ${ }^{(20)}$. Price promotions used by QSR chains include everyday value pricing (promotion of consistent low-price menu items), temporary price promotions (discounts offered for a limited time), and bundling separate items together in a combination at a lower price than the total of the individual items (hereafter referred to as 'combination deals') ${ }^{(21)}$. Price promotions at QSR chains have been identified as having an influence on customers' perceptions regarding the value of the offer and their purchase intentions ${ }^{(22,23)}$. There is also some evidence to show that price promotions influence consumer purchasing decisions in QSR chains ${ }^{(21,24)}$.

There have been only a limited number of studies that have investigated QSR price promotion strategies from a public health perspective ${ }^{(18,25-27)}$. A 2009 study conducted in $\mathrm{Canada}^{(28)}$ concluded that price promotions were effective in boosting fast-food sales by encouraging consumers to purchase more frequently or in larger quantities. Although lower-priced meals in this study were perceived by customers as better value for money, they were higher in energy density and lower in beneficial nutrients compared to higher-priced meals. In Australia, there has only been one small study, conducted in 2015, has examined pricing strategies of QSR chains with a health lens ${ }^{(27)}$. The study found that salads had the highest energy cost ( $\$$ per $\mathrm{kJ}$ ) of products available. However, the study did not examine temporary price promotions or the magnitude of price discounts on offer. Accordingly, there is very limited available data on the prevalence and types of price promotion strategies of QSR chains. This study aimed to contribute to addressing this gap by assessing the price promotions (including temporary price promotions and combination deals) offered by major QSR chains in Australia from an obesity prevention perspective. The objectives of the study were to estimate the (a) prevalence, types and magnitude of price promotions offered by the major QSR chains and (b) energy content and healthiness of the products included as part of price promotions.

\section{Methods}

This study used a cross-sectional design to audit food and beverage price promotions by major QSR chains in Melbourne, Australia. For the purpose of this study, a temporary price promotion refers to a reduction in price on a particular menu item or a group of menu items for a limited period of time ${ }^{(29,30)}$. Temporary price promotions are typically accompanied by communication of the promotion, which highlights the saving. In some cases, temporary price promotions indicate the time frame during which they apply, creating an expectation of time-limited availability $^{(29,30)}$. Sometimes, but not always, temporary price promotions are given a unique promotion name ('offer'), for example, 'KFC's Cheap as Chips' or 'Nando's \$11 WTF deal'. For this study, where a temporary price promotion included a group of menu items (e.g. a range of particular types of pizzas) as part of the same offer, we considered them as a single temporary price promotion.

A combination deal (also referred to as a 'combo meal') refers to several single-menu items offered together as a 'bundle', typically at a price lower than the sum of each individual item. In Australia, most combination deals comprised a main menu item (e.g. burger or fried chicken), and/or a side menu item (e.g. fries or side salad), and/or a drink.

\section{Sample selection}

The twelve largest QSR chains in Australia, by market share, were identified from the Euromonitor Passport International database (Table 1). QSR chains were selected if they had an outlet in the Melbourne Central Business District, Victoria, and had nutrition and pricing information for their products available online. Ten of the twelve QSR chains satisfied the selection criteria: (1) McDonald's, (2) KFC, (3) Pizza Hut, (4) Hungry Jack's, (5) Subway, (6) Domino's Pizza, (7) Red Rooster, (8) Oporto, (9) Nando's and (10) Grill'd. Two QSR chains were excluded because one (Chicken Treat) did not have an outlet in Melbourne and another (Taco Bell) did not declare nutritional information or pricing on their website.

\section{Data collection}

\section{Temporary price promotions}

All temporary price promotions from each chain were collected weekly for 13 weeks, between 25 November 2019 and 25 February 2020. Temporary price promotions were identified through three sources. Firstly, each QSR chain's website was reviewed weekly to identify and record attributes of price promotions offered. We varied the day of the week that this data collection occurred across the study period. Secondly, if the QSR chain had a dedicated mobile application (app), we registered for an account to identify and record details of any additional promotions specific to 
Australian fast-food price promotions

Table 1 Major QSR chains in Australia by market share, as of 2018

\begin{tabular}{|c|c|c|}
\hline Parent company/corporate owner & $\begin{array}{l}\text { QSR market share } \\
\%(\text { as of } 2018)^{\star}\end{array}$ & Chains (main type of food) \\
\hline McDonald's Corp. & $29 \cdot 1$ & McDonald's (burgers) \\
\hline Yum! Brands International Inc. & $12 \cdot 6$ & $\begin{array}{l}\text { KFC (chicken) } \\
\text { Pizza Hut (pizza) } \\
\text { Taco Bell (chicken) }\end{array}$ \\
\hline Restaurant Brands International Inc. & 8.7 & Hungry Jack's (burgers) \\
\hline Doctor's Associates Inc. & $6 \cdot 5$ & Subway (sandwiches) \\
\hline Domino’s Pizza Inc. & 5.9 & Domino's Pizza (pizza) \\
\hline Craveable Brands Ltd. & $4 \cdot 3$ & $\begin{array}{l}\text { Red Rooster (chicken) } \\
\text { Oporto (chicken) } \\
\text { Chicken Treat (chicken) }\end{array}$ \\
\hline Nando's Group Holdings Ltd. & 1.6 & Nando's (chicken) \\
\hline Grill'd Pty. Ltd. & $1 \cdot 3$ & Grill'd (burgers) \\
\hline
\end{tabular}

${ }^{*}$ Based on the market share in Australia from the Euromonitor Passport International database (2019).

the app. Finally, Frugal Feeds ${ }^{(31)}$, a third-party website that collates news and price promotion information of QSR chains through crowdsourcing, was checked each week to cross-check and supplement promotions identified through other sources. For each of the identified temporary price promotions, we recorded weekly in a pro forma spreadsheet: (1) name of promotion; (2) name of item(s) promoted; (3) nutrition information and portion size for all products involved in the promotion; (4) promoted price of each item; (5) regular price of each item; (6) date when the promotion was identified; (7) advertised start and end date of the promotion (where applicable); and (8) source where the price promotion was identified. This information was used to define a list of unique temporary price promotions offered by each chain. For each of the first 4 weeks of the data collection period, physical in-store visits (one store per chain, all located in the Melbourne Central Business District) were also conducted. This was to identify any discrepancies between the price promotions advertised online and in their physical chain outlets. No discrepancies were found over the 4-week period, after which physical in-store visits were ceased and price promotion data were collected through online sources only. The data from Frugal Feeds were found to directly match the data collected through the QSR chains' respective websites and/ or mobile apps.

\section{Combination deals}

Pricing data and nutrition information of all combination deals and related food items offered by each of the selected QSR chains was collected in February 2020 through their respective websites or apps. The combination deals were categorised according to whether they were part of the 'regular menu', 'breakfast menu' or 'children's menu' ('menu type'). Meal sizes were categorised based on the serving size of the included sides and/or drinks, as either 'small', 'medium', or 'large'. These classifications were typically based on chain-specific serving sizes. Where the chain only specified two available sizes, the smallest one (commonly identified as 'regular') was classified as 'medium' and the largest one as 'large'. The meal size of combination deals that were designed for sharing (e.g. included more than one 'main meal' item as part of the deal or were labelled as a 'family' size or 'for sharing') were classified as 'shared'. If a default selection of sides and/or drinks was identified for each combination deal (i.e. the item was automatically included as part of the combination deal unless the consumer chose a different option from a pre-specified list), this was noted. Nutrition and portion size information of all relevant menu items were recorded in a pro forma spreadsheet.

\section{Data analysis}

Product healthiness and energy contribution: the healthiness of products included in temporary price promotion offers and combination deals was assessed using the 2016 Victorian Department of Health and Human Services' Healthy Choices Framework ${ }^{(32)}$. The framework was developed to classify the healthiness of food and beverages into three categories utilising a traffic light system based on the product type and detailed nutrition criteria: (1) 'green' indicates the 'best choice' (most healthy); (2) 'amber' indicates a less healthy option, where consumers are advised to 'choose carefully' and (3) 'red' denotes an unhealthy option, where consumers are advised to 'limit their intake'. While the detailed criteria underpinning The Healthy Choices Framework are provided elsewhere ${ }^{(32)}$, some examples of the criteria are provided here to illustrate the way they were applied in this context. All deep-fried food items were classified as 'red', and any combination deals containing a deep-fried main or side item were classified as 'red'. Single main items, such as sandwiches and wraps, with the energy of $<=1000 \mathrm{~kJ} / 100 \mathrm{~g}$ were classified as 'amber'(32). Combination deals with energy content of $<=2500 \mathrm{~kJ}$ per serve without any deep-fried food items and with water selected as the drink option were also classified as 'amber'. Fresh vegetables, fruits, water and coffee with no added sweeteners were classified as 'green'. Salads containing a variety of vegetables and/or lean meat and/or reduced-fat cheese with 
either no or low-fat dressing were classified as 'green'. Salads with regular-fat cheese and/or crumbed or coated meats and/or oil-based dressing were classified as 'amber'. Salads that included deep-fried ingredients were classified as 'red'. Where menu items included a choice regarding products or condiments included, the healthiest available options were used to classify the healthiness of the menu item. All classifications of the healthiness of menu items were conducted by two authors (EL and GS) independently. Where there were discrepancies in the initial classification between the two authors, differences were resolved by discussion, and all final classifications were mutually agreed.

For the purpose of assessing product contribution to average daily recommended energy intake, an average recommended daily energy intake of $8700 \mathrm{~kJ}$ was used for adults, in line with regulations for menu kilojoule labelling in Victoria ${ }^{(33)}$ and $7100 \mathrm{~kJ}$ for children. Recommended children's energy intake was based on the average recommended daily energy intake using the reference values of an 8 -year-old boy $(7300 \mathrm{~kJ})$ and girl $(6900 \mathrm{~kJ})$ who lead a lightly active lifestyle (physical activity level of 1.6$)^{(34)}$.

\section{Temporary price promotions}

Unique temporary price promotion, that is, any temporary price promotion that was identified at least once in the 13week period, was the unit of analysis. Where a unique temporary price promotion applied to a group of menu items (each with different nutritional values and/or regular prices), we calculated the mean energy content and mean price saving based on the particular menu items eligible to be included as part of the offer. Unique temporary price promotions were categorised into 'product types' based on whether the promoted product(s) were considered to be: (1) main meal(s) for one person; (2) combination deal(s) for one person (consisting of one main menu item and at least one side or drink, intended for consumption by one person); (3) combination deal(s) for sharing (consisting of more than one main menu item, or a very large main menu item, such as 'family-sized' pizza and whole chickens, intended for consumption by more than one person); (4) side(s) and/or drink(s) only; and (5) dessert(s). Data on unique temporary price promotions were summarised by promotion type and chain as: (1) total number; (2) mean price; (3) mean magnitude of price reduction (in $\$$ and as a percentage of the regular menu price of the item(s) promoted); (4) mean energy content; (5) mean contribution to recommended daily energy intake; (6) mean energy cost (cents per $100 \mathrm{~kJ}$ ) and (7) healthiness classification. As it was not always possible to determine the specific start and end date of each temporary price promotion (e.g. if the temporary price promotion had already begun when our data collection commenced, or if no definitive end date was advertised), we did not perform a detailed analysis of the duration of temporary price promotions observed.

\section{Combination deals}

Combination deals were counted as unique based on a combination of the 'main meal' item(s) and the size (e.g. small, medium and large) of the sides and/or drinks. For example, a 'Small Big Mac ${ }^{\circledR}$ meal' and a 'Large Big Mac ${ }^{\circledR}$ meal' from McDonald's were each counted as separate combination deals. Each combination deal usually involved a range of sides and/or drinks available for selection. Therefore, we calculated the selection of items that would result in the lowest and highest values for (a) price savings and (b) energy content. Combination deals for each menu type ('regular menu', 'breakfast menu' and 'children's menu') were reported by the QSR chain and by the meal size. Data on combination deals were summarised for the lowest and highest options as: (1) mean magnitude and percentage of price savings, calculated with reference to the cumulative price of the individual menu items included in the combination deal; (2) mean energy content; (3) mean contribution to average recommended daily energy intake; (4) number of combination deals that exceeded $30 \%$ of average recommended daily energy intake; (5) mean energy cost (cents per $100 \mathrm{~kJ}$ ); (6) mean incremental energy cost, calculated as the difference in the energy cost (cents per $100 \mathrm{~kJ}$ ) of the combination deal and the primary main meal item (e.g. burger, fried chicken pieces) included as part of the combination deal, where applicable; and (7) healthiness classification. The metrics related to energy intake contribution and energy costs were not calculated for combination deals with a 'meal size' classified as 'shared'.

Data for each of the outcomes of interest were summarised by QSR chain using means and $95 \% \mathrm{CI}$. Where results are reported for all QSR chains combined, means and 95\% CI were estimated using linear mixed models with QSR chain as a random effect to account for clustering. All analyses were performed in Stata 16.1.

\section{Results}

\section{Temporary price promotions}

One hundred and ninety-six ( $n$ 196) temporary price promotions were identified during the 13-week period: 75 on 'main menu items', 25 on 'combination deals for one person', 54 on 'combination deals for sharing', 30 on 'sides and/or drinks', and 12 on 'desserts' (Table 2). Ninety-eight of the temporary price promotions applied to more than one menu item (average of three menu items per temporary price promotion).

Mean price reductions (as a proportion of regular prices) were similar across product types, ranging from $36.8 \%$ for 'desserts' to $47.7 \%$ for 'sides and/or drinks'. Pricepromoted menu items also had similar costs per kJ across product types, ranging from 17 cents per $100 \mathrm{~kJ}$ for 'combination deals for sharing' to 24 cents per $100 \mathrm{~kJ}$ for 'combination deals for one person'. Price-promoted products, on 


\section{Public Health Nutrition}

Table 2 Unique temporary price promotions offered by ten of the major QSR chains in Australia between 25 November 2019 and 25 February 2020 (13 weeks)

\begin{tabular}{|c|c|c|c|c|c|c|c|c|c|c|c|c|c|c|}
\hline Product type & $\begin{array}{l}\text { Total number of } \\
\text { unique temporary } \\
\text { price promotions } \\
\text { identified }\end{array}$ & $\begin{array}{l}\text { Mean } \\
\text { promotion } \\
\text { price (AU } \\
\$ \text { ) }\end{array}$ & $95 \% \mathrm{Cl}$ & $\begin{array}{l}\text { Mean price reduction of } \\
\text { promoted menu item(s) } \\
\text { relative to regular price } \\
\text { (AU\$) }\end{array}$ & $95 \% \mathrm{Cl}$ & $\begin{array}{l}\text { Mean percent- } \\
\text { age (\%) price } \\
\text { reduction of } \\
\text { promoted menu } \\
\text { item(s) relative } \\
\text { to regular price }\end{array}$ & $95 \% \mathrm{Cl}$ & $\begin{array}{l}\text { Mean energy } \\
\text { content (kJ) of } \\
\text { promoted menu } \\
\text { item(s) }\end{array}$ & $95 \% \mathrm{Cl}$ & $\begin{array}{l}\text { Mean contribution of promoted } \\
\text { menu item(s) to average daily } \\
\text { recommended energy intake } \\
(\%)\end{array}$ & $95 \% \mathrm{Cl}$ & $\begin{array}{l}\text { Mean } \\
\text { energy cost } \\
\text { (cents per } \\
100 \mathrm{~kJ} \text { ) }\end{array}$ & $\begin{array}{c}95 \% \\
\mathrm{Cl}\end{array}$ & $\begin{array}{l}\text { Classification as } \\
\text { per Healthy } \\
\text { Choices } \\
\text { Frameworkt }\end{array}$ \\
\hline $\begin{array}{l}\text { Main meal } \\
\text { items only }\end{array}$ & 75 & $10 \cdot 26$ & $6 \cdot 76,13.75$ & $7 \cdot 31$ & $5 \cdot 25,9 \cdot 38$ & $41 \cdot 7$ & $36 \cdot 9,46 \cdot 4$ & 5898 & 3446,8350 & 67.8 & $39 \cdot 6,96 \cdot 0$ & 20 & 16,23 & $\begin{array}{l}97 \% \text { Red, } \\
3 \% \text { Amber }\end{array}$ \\
\hline $\begin{array}{l}\text { Combination } \\
\text { deals for } \\
\text { one } \\
\text { person }\end{array}$ & 25 & 7.03 & $5 \cdot 80,8 \cdot 26$ & 5.68 & $3.88,7.49$ & $42 \cdot 3$ & $36 \cdot 3,49 \cdot 1$ & 3618 & 2698,4539 & 41.6 & $31 \cdot 0,52 \cdot 2$ & 24 & 13,34 & $\begin{array}{l}96 \% \text { Red, } \\
4 \% \text { Amber }\end{array}$ \\
\hline $\begin{array}{l}\text { Combination } \\
\text { deals for } \\
\text { sharing }\end{array}$ & 54 & 23.74 & $19 \cdot 15,28 \cdot 32$ & 14.11 & $10 \cdot 08,18 \cdot 13$ & 37.0 & $28 \cdot 5,45 \cdot 4$ & 14661 & 10736,18586 & NA‡ & & 17 & 15,18 & $100 \%$ Red \\
\hline $\begin{array}{l}\text { Sides and/or } \\
\text { drinks }\end{array}$ & 30 & 4.51 & $3.33,5 \cdot 69$ & 4.01 & $2 \cdot 37,5 \cdot 66$ & 47.7 & $42 \cdot 4,53 \cdot 0$ & 2974 & 1592,4357 & 34.2 & $18 \cdot 3,50 \cdot 1$ & 18 & 12,23 & $\begin{array}{l}90 \% \text { Red, } \\
10 \% \text { Green§ }\end{array}$ \\
\hline Desserts & 12 & 8.92 & $1 \cdot 66,16 \cdot 19$ & 2.73 & $1 \cdot 31,4 \cdot 15$ & 36.8 & $15 \cdot 9,57 \cdot 8$ & 3964 & 1694,6235 & $45 \cdot 6$ & $19 \cdot 5,71 \cdot 7$ & 18 & 11,25 & $100 \%$ Red \\
\hline
\end{tabular}

NA, not applicable.

Mean and $95 \%$ Cl estimated under a linear mixed model with chain as random effect.

*The average daily recommended energy intake for an adult is $8700 \mathrm{~kJ}$.

†Classification based on the 2016 Victorian Department of Health and Human Services' Healthy Choices Framework ${ }^{(32}$

¥Not calculated due to the 'sharing' nature of the combination deals.

$\S$ Only drinks without added sugar (e.g. coffee without added sugar). 
average, contributed greater than a third of the average daily recommended energy intake for adults, with pricepromoted 'main meal items' contributing $67.8 \%$ on average and price-promoted desserts contributing $45.6 \%$ on average. Almost all (97\%) of the temporary price-promoted items were classified as 'red' (unhealthy), with three price-promoted items classified as 'green' (healthy) on the provision that no sugar was added to price-promoted hot drinks (e.g. coffee without sugar), and three pricepromoted items classified as 'amber' (less healthy option) as the price promoted sandwiches had the energy of less than $1000 \mathrm{~kJ} / 100 \mathrm{~g}$.

McDonald's ( $n$ 51) offered the highest number of temporary price promotions during the period, followed by Hungry Jack's ( $n$ 38), and Domino's ( $n$ 34) (Table 3). Nando's and Grill'd only had one temporary price promotion each during the study period. There was substantial variation with regard to promotion price and the magnitude of price savings across the selected QSR chains. Although Grill'd had only one price promotion, it offered the highest price reduction (as a proportion of regular prices) (50\%). This was followed by McDonald's (48.4\%), KFC and Red Rooster (both $45.4 \%$ ). Pizza Hut and Subway offered the lowest percentage price reduction (19.6\% and $23.7 \%$, respectively). Subway was the only QSR chain that had all its price-promoted items classified as 'amber'. Subway's price-promoted items also had the lowest energy content (1558 kJ) on average, although the mean energy cost for price-promoted items was higher at Subway ( 45 cents per $100 \mathrm{~kJ}$ ) compared to most of the other chains. A breakdown of the energy content of price-promoted items in the selected QSR chains can be found in Supplemental Table 1.

The duration of the temporary price promotions varied across chains. Some QSR chains did not include a start and end date to their promotions. Three QSR chains (Hungry Jack's, Dominos and Pizza Hut) adopted a voucher system for their temporary price promotion campaigns, whereby a promotion ran for periods from 6 weeks to 4 months, with customers given a limited number of vouchers to use during that period. For some QSR chains, the same set of price promotions were observed to be repeated consecutively. For example, during the 13-week monitoring period, Hungry Jack's had the same set of price promotions for three promotion cycles with each cycle running for 10 weeks through their voucher system.

\section{Combination deals - 'regular menus'}

On 'regular menus', a total of 537 combination deals were identified (Table 4). Hungry Jack's offered the most combination deals ( $n$ 179), followed by McDonald's ( $n$ 138) and KFC ( $n$ 103). Three QSR chains (Domino's, Grill'd and Nando's) did not offer combination deals on their regular menus. All the combination deals that included a drink had the option to select from a list of soft drinks, juices and/or water, with no default drink indicated. McDonald's was the only QSR chain that provided a 'green' (healthy) salad as one of the available options for sides, while the other six QSR chains that offered combination deals only offered chips/fries as the side item. All combination meals on the 'regular menus' were classified as 'red' (unhealthy).

The magnitude of price savings on combination deals varied by chain and meal size, as well as by side or drink options selected (Table 4). When comparing mediumsized combination deals, based on the lowest-priced side and drink options, Red Rooster had the greatest average proportional price savings $(35.0 \%)$, followed by Pizza Hut (23.2\%) and Oporto (20.3\%). Pizza Hut's sharing-sized combination deals were more expensive $(6.2 \%$ higher in price compared to the price of the individual items) if the lowest-priced menu items were selected as part of the combination deal. However, when selecting the highest-priced items in the combination deals, Pizza Hut offered a $21.4 \%$ mean price saving.

Across all of the selected QSR chains, the magnitude of price savings varied by the size of the combination deal (e.g. small, medium and large), with the small-sized combination deals often yielding greater savings. For example, the mean price reduction for McDonald's small-sized combination deals with the lowest-priced side and drink options was $13.2 \%$, while the mean price reduction was $12.0 \%$ and $8.3 \%$ for their medium-sized and large-sized combination deals, respectively. Similarly, the mean price reduction for McDonald's small-sized combination deals with the highest-priced side and drink options was $29 \%$, while the mean price reduction was $23.9 \%$ and $20.8 \%$ for their medium-sized and large-sized combination deals, respectively. The same pattern was observed for KFC, Subway and Red Rooster. For Hungry Jack's and KFC, the value and proportion of the mean price savings for small-, medium- and large-sized combination meals was much lower than on shared combination meals, although this was not the case for Red Rooster, Pizza Hut and Oporto. Refer to Fig. 1.

With regard to energy content, $69 \%$ of combination deals (excluding those with a 'meal size' classified as 'shared') provided greater that $30 \%$ of an adult's average recommended daily energy intake (equivalent to 2610 $\mathrm{kJ}$ ) if the lowest-energy options were selected (see online Supplemental Table 2). This increased to $99 \%$ of combination deals if the highest-energy options were selected. When comparing small-sized combination deals, Hungry Jack's had the highest average energy content, with their small-sized combination deal contributing almost half (48.4\%) of an adult's average recommended daily energy intake if the lowest-energy options were selected, and more than half (57.1\%) of an adult's average daily recommended energy intake if the highest-energy options were selected (Table 4). At McDonald's, if the low-kilojoule single-sized salad option was selected as part of their 


\section{Public Health Nutrition}

Table 3 Temporary price promotions offered by ten major QSR chains in Australia between 25 November 2019 and 25 February 2020 (13 weeks)

\begin{tabular}{|c|c|c|c|c|c|c|c|c|c|c|c|c|c|c|}
\hline QSR chain & $\begin{array}{l}\text { Total number of } \\
\text { unique temporary } \\
\text { price promotions } \\
\text { identified }\end{array}$ & $\begin{array}{l}\text { Mean } \\
\text { promotion } \\
\text { price } \\
\text { (AU \$) }\end{array}$ & $95 \% \mathrm{Cl}$ & $\begin{array}{c}\text { Mean price reduction of } \\
\text { promoted menu item(s) } \\
\text { relative to regular price } \\
\text { (AU\$) }\end{array}$ & $95 \% \mathrm{Cl}$ & $\begin{array}{l}\text { Mean percentage }(\%) \\
\text { price reduction of pro- } \\
\text { moted menu item(s) rela- } \\
\text { tive to regular price }\end{array}$ & $95 \% \mathrm{Cl}$ & $\begin{array}{c}\text { Mean energy } \\
\text { content (kJ) of } \\
\text { promoted } \\
\text { menu item(s) }\end{array}$ & $95 \% \mathrm{Cl}$ & $\begin{array}{l}\text { Mean contribution of } \\
\text { promoted menu } \\
\text { item(s) to average } \\
\text { daily recommended } \\
\text { energy intake }(\%)\end{array}$ & $95 \% \mathrm{Cl}$ & $\begin{array}{l}\text { Mean } \\
\text { energy } \\
\text { cost (cents } \\
\text { per } 100 \\
\text { kJ) }\end{array}$ & $\begin{array}{c}95 \% \\
\mathrm{Cl}\end{array}$ & $\begin{array}{c}\text { Classification } \\
\text { as per Healthy } \\
\text { Choices } \\
\text { Framework } \dagger\end{array}$ \\
\hline McDonald's & 51 & 5.02 & $3.88,6.17$ & 4.19 & $3 \cdot 48,4.91$ & 48.4 & $44 \cdot 5,52 \cdot 2$ & 2668 & 2184,3152 & 30.7 & $25 \cdot 1,36 \cdot 2$ & 17 & 15,20 & $\begin{array}{l}96 \% \text { Red, } \\
4 \% \text { Green }\end{array}$ \\
\hline $\begin{array}{l}\text { Hungry } \\
\text { Jack's }\end{array}$ & 38 & 8.77 & $6.91,10.63$ & 5.93 & $4 \cdot 54,7 \cdot 33$ & 41.2 & $38 \cdot 9,43 \cdot 4$ & 5155 & 4090,6221 & $59 \cdot 3$ & $47 \cdot 0,71 \cdot 5$ & 18 & 16,19 & $\begin{array}{l}97 \% \text { Red } \\
3 \% \text { Green }\end{array}$ \\
\hline Domino's & 34 & 12.08 & $8 \cdot 75,15 \cdot 40$ & $10 \cdot 39$ & $7 \cdot 46,13 \cdot 31$ & 43.0 & $38 \cdot 6,47 \cdot 3$ & 8560 & 6408,10712 & 98.4 & $73 \cdot 7,123 \cdot 1$ & 14 & 12,17 & $100 \%$ Red \\
\hline Pizza Hut & 23 & 29.03 & $25 \cdot 41,32 \cdot 65$ & $7 \cdot 20$ & $4.91,9.48$ & 19.6 & $13 \cdot 5,25 \cdot 7$ & 19775 & 16367,23183 & $227 \cdot 3$ & $188 \cdot 1,266 \cdot 5$ & 16 & 14,19 & $100 \%$ Red \\
\hline KFC & 22 & 12.54 & $8 \cdot 72,16 \cdot 37$ & 9.56 & $6 \cdot 79,12 \cdot 33$ & 45.4 & $39 \cdot 6,51 \cdot 3$ & 6816 & 4680,8952 & 78.4 & $53 \cdot 8,102 \cdot 9$ & 18 & 16,21 & $100 \%$ Red \\
\hline $\begin{array}{l}\text { Red } \\
\text { Rooster }\end{array}$ & 21 & $15 \cdot 18$ & $10.68,19.68$ & $12 \cdot 14$ & $8.76,15.52$ & 45.4 & $39 \cdot 0,51 \cdot 9$ & 9342 & 6512,12172 & $107 \cdot 4$ & $74 \cdot 9,139.9$ & 17 & 15,20 & $100 \%$ Red \\
\hline Subway & 3 & 6.98 & $4.44,9.53$ & 2.23 & $0.21,4.25$ & 23.7 & $14 \cdot 0,33 \cdot 5$ & 1558.17 & 1242,1874 & 17.9 & $14 \cdot 3,21 \cdot 6$ & 45 & 22,68 & $100 \%$ Amber \\
\hline Oporto & 2 & $10 \cdot 38$ & $-3.92,24.67$ & 7.13 & $-19 \cdot 88,34 \cdot 13$ & 40.2 & $-85 \cdot 0,165 \cdot 3$ & 5090 & 1151,9029 & 58.5 & $13 \cdot 2,103 \cdot 8$ & 21 & $-23,65$ & $100 \%$ Red \\
\hline Nando's & 1 & 11.00 & - & 4.85 & - & 30.6 & - & 4216 & - & 48.5 & - & 26 & - & $100 \%$ Red \\
\hline Grill'd & 1 & 15.08 & - & 15.08 & - & $50 \cdot 0$ & - & 6827 & - & 78.5 & - & 22 & - & $100 \%$ Red \\
\hline
\end{tabular}

QSR, quick service restaurant.

The average daily recommended energy intake for an adult is $8700 \mathrm{~kJ}$.

†Classification based on the 2016 Victorian Department of Health and Human Services' Healthy Choices Framework ${ }^{(32) .}$

fOnly drinks without added sugar (e.g. coffee without added sugar). 
Table 4 Price savings, energy content and healthiness of combination deals available on 'regular menus' of selected major QSR chains in Australia (February 2020)

\begin{tabular}{|c|c|c|c|c|c|c|c|c|c|c|c|c|c|c|c|c|c|c|c|}
\hline \multirow[b]{2}{*}{ QSR chain } & \multirow[b]{2}{*}{$\begin{array}{l}\text { Meal } \\
\text { size }\end{array}$} & \multirow[b]{2}{*}{$\begin{array}{c}\text { Number of } \\
\text { combination } \\
\text { deals }\end{array}$} & \multicolumn{8}{|c|}{ Price saving per combination deal, relative to price of individual items } & \multicolumn{8}{|c|}{ Energy content per combination deal } & \multirow[b]{2}{*}{$\begin{array}{c}\text { Classification } \\
\text { as per } \\
\text { Healthy } \\
\text { Choices } \\
\text { Framework† }\end{array}$} \\
\hline & & & $\begin{array}{l}\text { Mean } \\
\text { reduction } \\
(\$) \text { - low- } \\
\text { est-priced } \\
\text { option }\end{array}$ & $95 \% \mathrm{Cl}$ & $\begin{array}{l}\text { Mean } \\
\text { reduction } \\
\text { (\% of } \\
\text { price of } \\
\text { individual } \\
\text { items) - } \\
\text { lowest- } \\
\text { priced } \\
\text { option }\end{array}$ & $95 \% \mathrm{Cl}$ & $\begin{array}{l}\text { Mean } \\
\text { reduction } \\
(\$)- \\
\text { highest- } \\
\text { priced } \\
\text { option }\end{array}$ & $95 \% \mathrm{Cl}$ & $\begin{array}{c}\text { Mean } \\
\text { reduction } \\
\text { (\% of } \\
\text { price of } \\
\text { individual } \\
\text { items) - } \\
\text { highest- } \\
\text { priced } \\
\text { option }\end{array}$ & $95 \% \mathrm{Cl}$ & $\begin{array}{c}\text { Mean } \\
\text { energy } \\
\text { content } \\
\text { (kJ) - } \\
\text { lowest- } \\
\text { energy } \\
\text { option }\end{array}$ & $95 \% \mathrm{Cl}$ & $\begin{array}{l}\text { Mean contribu- } \\
\text { tion to average } \\
\text { daily recom- } \\
\text { mended } \\
\text { energy intake1 } \\
\text { - lowest- } \\
\text { energy option } \\
(\%)\end{array}$ & $95 \% \mathrm{Cl}$ & $\begin{array}{c}\text { Mean } \\
\text { energy } \\
\text { content } \\
\text { (kJ) - } \\
\text { highest- } \\
\text { energy } \\
\text { option }\end{array}$ & $95 \% \mathrm{Cl}$ & $\begin{array}{l}\text { Mean contribu- } \\
\text { tion to average } \\
\text { daily recom- } \\
\text { mended } \\
\text { energy intake* } \\
\text { - highest- } \\
\text { energy option } \\
(\%)\end{array}$ & $95 \% \mathrm{Cl}$ & \\
\hline \multirow{4}{*}{$\begin{array}{l}\text { Hungry Jack's } \\
\qquad(n \text { 179) }\end{array}$} & Small & 57 & 1.00 & $0.54,1.46$ & 8.2 & $5 \cdot 2,11 \cdot 1$ & 1.97 & $1 \cdot 49,2.45$ & $15 \cdot 3$ & $12 \cdot 5,18 \cdot 1$ & 4214 & 3842,4585 & 48.4 & $44 \cdot 2,52 \cdot 7$ & 4965 & 4586,5343 & $57 \cdot 1$ & $52 \cdot 7,61 \cdot 4$ & $100 \%$ Red \\
\hline & Medium & 57 & 2.66 & $2 \cdot 16,3 \cdot 17$ & $18 \cdot 3$ & $15 \cdot 7,20.9$ & 3.12 & $2.61,3.63$ & 20.8 & $18 \cdot 2,23 \cdot 4$ & 4448 & 4074,4821 & $51 \cdot 1$ & $46 \cdot 8,55 \cdot 4$ & 5406 & 5023,5789 & $62 \cdot 1$ & $57 \cdot 7,66 \cdot 5$ & $100 \%$ Red \\
\hline & Large & 57 & 2.70 & $2 \cdot 18,3 \cdot 21$ & $17 \cdot 2$ & $14 \cdot 7,19 \cdot 8$ & 2.70 & $2 \cdot 18,3 \cdot 21$ & $17 \cdot 2$ & $14 \cdot 7,19 \cdot 8$ & 4985 & 4620,5350 & 57.3 & $53 \cdot 1,61 \cdot 5$ & 6335 & 5970,6700 & $72 \cdot 8$ & $68 \cdot 6,77 \cdot 0$ & $100 \%$ Red \\
\hline & Shared $\neq$ & 8 & 7.42 & $3.02,11.82$ & 30.9 & $24 \cdot 3,37 \cdot 4$ & 7.76 & $3 \cdot 20,12 \cdot 31$ & 31.8 & $25 \cdot 3,38 \cdot 3$ & 7359 & 4459,10260 & NA§ & & 8066 & 5013,11119 & NA§ & & $100 \%$ Red \\
\hline \multirow{3}{*}{$\begin{array}{l}\text { McDonald's } \\
\qquad(n \text { 138) }\end{array}$} & Small & 46 & 1.59 & $1.43,1.76$ & $13 \cdot 2$ & $11 \cdot 6,14 \cdot 8$ & 4.29 & $4 \cdot 13,4.46$ & 29.0 & $27 \cdot 4,30 \cdot 7$ & 2389 & 2138,2640 & 27.5 & $24 \cdot 6,30 \cdot 3$ & 3693 & 3442,3944 & 42.5 & $39 \cdot 6,45 \cdot 3$ & $100 \%$ Red \\
\hline & Medium & 46 & 1.54 & $1 \cdot 43,1 \cdot 65$ & 12.0 & $11 \cdot 0,12 \cdot 9$ & 3.54 & 3.43, 3.65 & 23.9 & $22 \cdot 8,25 \cdot 0$ & 2389 & 2138,2640 & 27.5 & $24 \cdot 6,30 \cdot 3$ & 4299 & 4049,4550 & 49.4 & $46 \cdot 5,52 \cdot 3$ & $100 \%$ Red \\
\hline & Large & 46 & 1.09 & $0.99,1 \cdot 20$ & 8.3 & $7 \cdot 4,9.2$ & 3.14 & $3 \cdot 04,3 \cdot 25$ & 20.8 & $19 \cdot 8,21 \cdot 7$ & 2389 & 2138,2640 & 27.5 & $24 \cdot 6,30 \cdot 3$ & 4987 & 4736,5238 & 57.3 & $54 \cdot 4,60 \cdot 2$ & $100 \%$ Red \\
\hline \multirow[t]{3}{*}{ KFC $(n 103)$} & Medium & 49 & 1.63 & $1 \cdot 34,1.92$ & $12 \cdot 8$ & $11 \cdot 0,14 \cdot 5$ & $5 \cdot 19$ & $4 \cdot 57,5 \cdot 81$ & 32.0 & $30 \cdot 0,33 \cdot 9$ & 2834 & 2594,3074 & 32.6 & $29 \cdot 8,35 \cdot 3$ & 4828 & 4467,5188 & 55.5 & $51 \cdot 3,59 \cdot 6$ & $100 \%$ Red \\
\hline & Large & 48 & 0.45 & $0.01,0.89$ & $2 \cdot 1$ & $-1 \cdot 3,5 \cdot 5$ & 5.02 & $4 \cdot 35,5 \cdot 69$ & $26 \cdot 8$ & $24 \cdot 7,29 \cdot 0$ & 2854 & 2613,3096 & 32.8 & $30 \cdot 0,35 \cdot 6$ & 6497 & 6133,6862 & 74.7 & $70 \cdot 5,78.9$ & $100 \%$ Red \\
\hline & Shared $\neq$ & 6 & 13.46 & $6.72,20.21$ & $27 \cdot 8$ & $19 \cdot 2,36 \cdot 4$ & 22.40 & $14 \cdot 36,30 \cdot 43$ & 39.7 & $34 \cdot 3,45 \cdot 2$ & 14315 & 9377,19254 & NA§ & & 23387 & 14 572, 32202 & NA§ & & $100 \%$ Red \\
\hline \multirow[t]{2}{*}{ Subway ( $n 52)$} & Medium & 30 & 1.55 & $1.55,1.55$ & $10 \cdot 3$ & $10 \cdot 1,10 \cdot 6$ & 1.55 & $1.55,1.55$ & $10 \cdot 3$ & $10 \cdot 1,10 \cdot 6$ & 3383 & 3097,3669 & 38.9 & $35 \cdot 6,42 \cdot 2$ & 4447 & 4161,4733 & 51.1 & $47 \cdot 8,54 \cdot 4$ & $100 \%$ Red \\
\hline & Large & 22 & 1.55 & $1 \cdot 55,1 \cdot 55$ & 8.6 & $8.4,8.8$ & 1.55 & $1 \cdot 55,1 \cdot 55$ & 8.6 & $8.4,8.8$ & 4492 & 4093,4890 & 51.6 & $47 \cdot 1,56 \cdot 2$ & 5556 & 5157,5954 & 63.9 & $59 \cdot 3,68 \cdot 4$ & $100 \%$ Red \\
\hline Red Rooster & Small & 3 & $6 \cdot 22$ & $2.99,9.45$ & 45.4 & $35 \cdot 7,55 \cdot 2$ & $6 \cdot 22$ & $2.99,9.45$ & 45.4 & $35 \cdot 7,55 \cdot 2$ & 2844 & 1461,4226 & 32.7 & $16 \cdot 8,48 \cdot 6$ & 329 & 1362,5218 & 37.8 & $15 \cdot 7,60 \cdot 0$ & $100 \%$ Red \\
\hline \multirow[t]{2}{*}{ (n 27) } & Medium & 19 & 7.05 & $5.50,8.61$ & 35.0 & $30.5,39.6$ & 7.05 & $5.50,8.61$ & 35.0 & $30.5,39.6$ & 4066 & 3544,4589 & 46.7 & $40 \cdot 7,52 \cdot 7$ & 4887 & 4311,5462 & $56 \cdot 2$ & $49 \cdot 6,62 \cdot 8$ & $100 \%$ Red \\
\hline & Sharedf & 5 & 8.58 & $4.52,12.64$ & 31.0 & $21 \cdot 0,41 \cdot 1$ & 8.58 & $4.52,12.64$ & 31.0 & $21 \cdot 0,41 \cdot 1$ & 6498 & 5267,7730 & NA§ & & 7933 & 6040,9825 & NA§ & & $100 \%$ Red \\
\hline \multirow[t]{2}{*}{ Pizza Hut ( $(n$ 22) } & Medium & 7 & 2.90 & $1 \cdot 40,4.40$ & 23.2 & $13.9,32.5$ & 2.90 & $1 \cdot 40,4 \cdot 40$ & 23.2 & $13 \cdot 9,32 \cdot 5$ & 3366 & 2387,4346 & 38.7 & $27 \cdot 4,50 \cdot 0$ & 4585 & 3565,5606 & 52.7 & $41 \cdot 0,64 \cdot 4$ & $100 \%$ Red \\
\hline & Shared $\neq$ & 15 & -1.60 & $-3.75,0.55$ & $-6 \cdot 2$ & $-13 \cdot 0,0.6$ & 11.40 & $7.32,15 \cdot 48$ & $21 \cdot 4$ & $17 \cdot 1,25 \cdot 7$ & 17191 & 13525,20857 & NA§ & & 26378 & 20 158, 32599 & NA§ & & $100 \%$ Red \\
\hline \multirow[t]{2}{*}{ Oporto ( $n$ 16) } & Medium & 12 & 3.88 & $3 \cdot 28,4 \cdot 47$ & $20 \cdot 3$ & $18 \cdot 2,22 \cdot 3$ & 4.01 & $3 \cdot 25,4 \cdot 77$ & 20.7 & $18 \cdot 1,23 \cdot 4$ & 4774 & 4316,5232 & 54.9 & $49 \cdot 6,60 \cdot 1$ & 5713 & 5038,6388 & 65.7 & $57 \cdot 9,73 \cdot 4$ & $100 \%$ Red \\
\hline & Shared $\neq$ & 4 & 12.84 & $0.52,26 \cdot 20$ & 25.4 & $3.8,47 \cdot 1$ & $15 \cdot 21$ & $-2 \cdot 66,33.08$ & 27.9 & $2.2,53.6$ & 12598 & 8463,16732 & NA§ & & 17662 & 4367,30958 & NA§ & & $100 \%$ Red \\
\hline
\end{tabular}

QSR, quick service restaurant; NA, not applicable.

Domino's, Grill'd and Nando's did not offer combination deals.

"The average daily recommended energy intake for an adult is $8700 \mathrm{~kJ}$.

(ictorian based on the 2016 Victorian Department of Health and Human Services' Healthy Choices Framework (32).

§Not calculated due to the 'sharing' nature of the combination deals. 
60

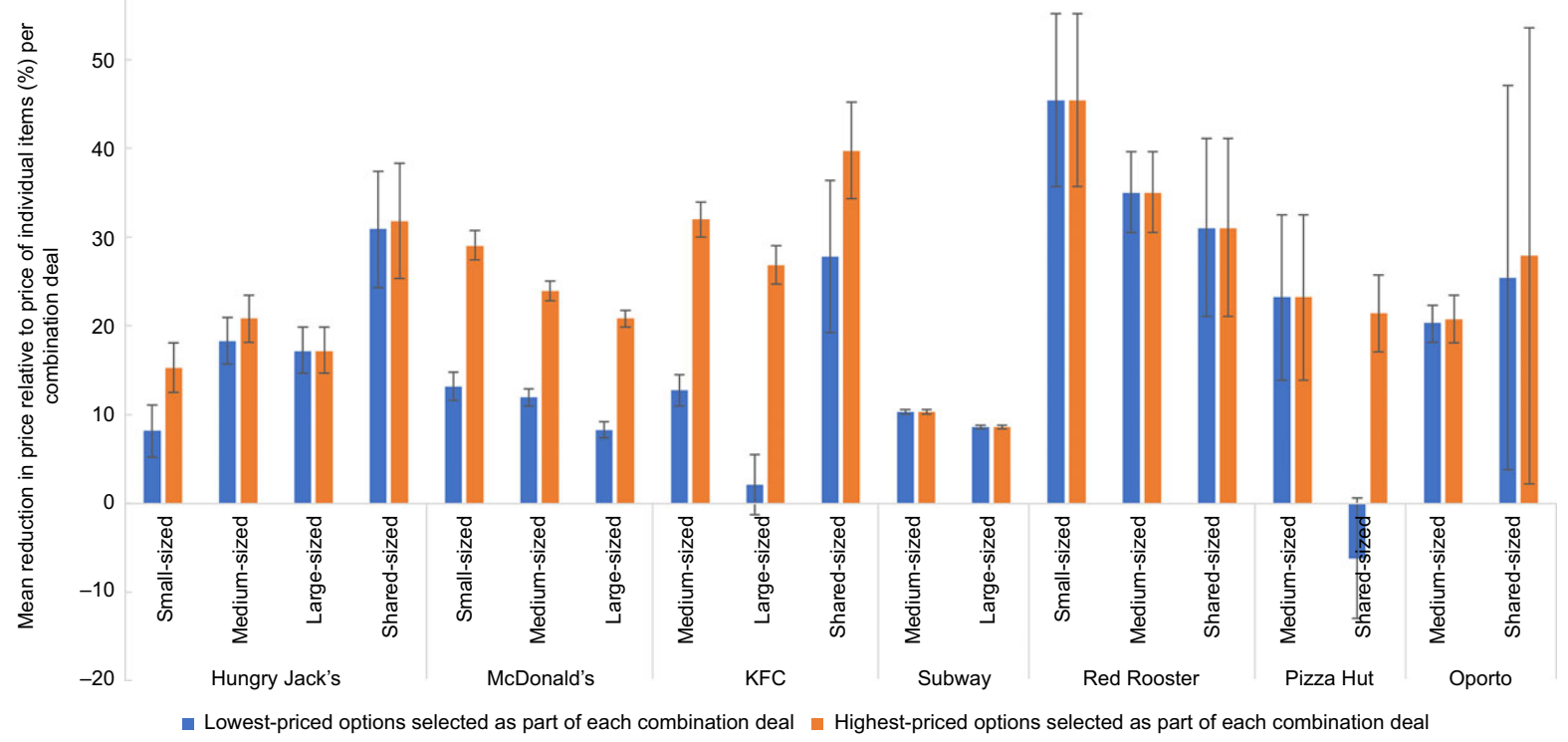

Fig. 1 (colour online) Mean percentage price reduction of combination deals (relative to the price of individual items) on 'regular menus' of selected major QSR chains in Australia, by meal size and product options selected as part of the combination deal, with $95 \%$ Cl (February 2020)

combination deals, with water or other sugar-free drink, they offered the lowest energy content combination meals on average, contributing to $27.5 \%$ of an adult's average daily recommended energy intake regardless of the size of the combination deal. However, if the highest-energy sides and drinks were selected at McDonald's, the mean contribution of combination deals to average daily recommended energy intake would increase to $42.5 \%$ for smallsized meals, $49.4 \%$ for medium-sized meals and $57.3 \%$ for large-sized meals. Large-sized combination deals with the highest-energy sides and drinks contributed substantially to average daily recommended energy intake at Hungry Jack's $($ mean $=72.8 \%)$ and KFC $($ mean $=74.7 \%)$. Refer to Fig. 2.

In considering energy cost (price per kJ), we found that combination deals provided substantially cheaper energy compared with relevant stand-alone main meal items. However, this was only the case when the highest-energy sides and drinks (e.g. chips and sugary drink) were selected, not when lowest-energy sides and drinks (e.g. salad and/or water or sugar-free beverages) were chosen (see online Supplemental Table 3).

\section{Combination deals - 'children's menus'}

A total of 34 combination deals, from eight of the ten QSR chains, were identified on 'children's menus' (refer to Table 5). McDonald's had the most combination deals on their children's menu ( $n 7)$, while KFC had the fewest ( $n$ 2 ). All but one (KFC) of the eight QSR chains offered only one size of combination deal on their children's menu.
Across the selected QSR chains, the mean percentage of price savings relative to the price of individual items included in children's combination deals were $21.3 \%$ for the lowest-priced options and $37.5 \%$ for the highest-priced options. The mean energy content of children's combination deals was $1538 \mathrm{~kJ}$ for the lowest-energy options and $2472 \mathrm{~kJ}$ for the highest-energy options. The mean contribution of combination deals to the average recommended daily energy content of an 8-year-old child was $21.7 \%$ if the lowest-energy option of the side and drink were selected. However, this rose to a mean contribution of $34.8 \%$ if the highest-energy option of the side and drink were selected, with combination deals from several chains, including McDonald's, Hungry Jack's and KFC, contributing over $40 \%$. $56 \%$ of combination deals contributed greater than $30 \%$ of an 8-year-old child's average recommended daily energy intake (equivalent to $2130 \mathrm{~kJ}$ ) if the highest-energy options were selected (see online Supplemental Table 4).

As was the case in relation to 'regular menus' and 'breakfast menus' (see online Supplemental Table 5), energy cost (price per kJ) decreased substantially with the purchase of a combination deal (compared with relevant stand-alone main meal items) when the highest-energy sides and drinks (e.g. chips and sugary drink) were selected. However, this was not the case not when lowest-energy sides and drinks (e.g. salad and/or water or sugar-free beverages) were selected (see online Supplemental Table 6).

Overall, $80 \cdot 8 \%$ of the children's combination deals were classified as 'red' (unhealthy). All of Subway's children's combination deals were classified as 'amber' when the 


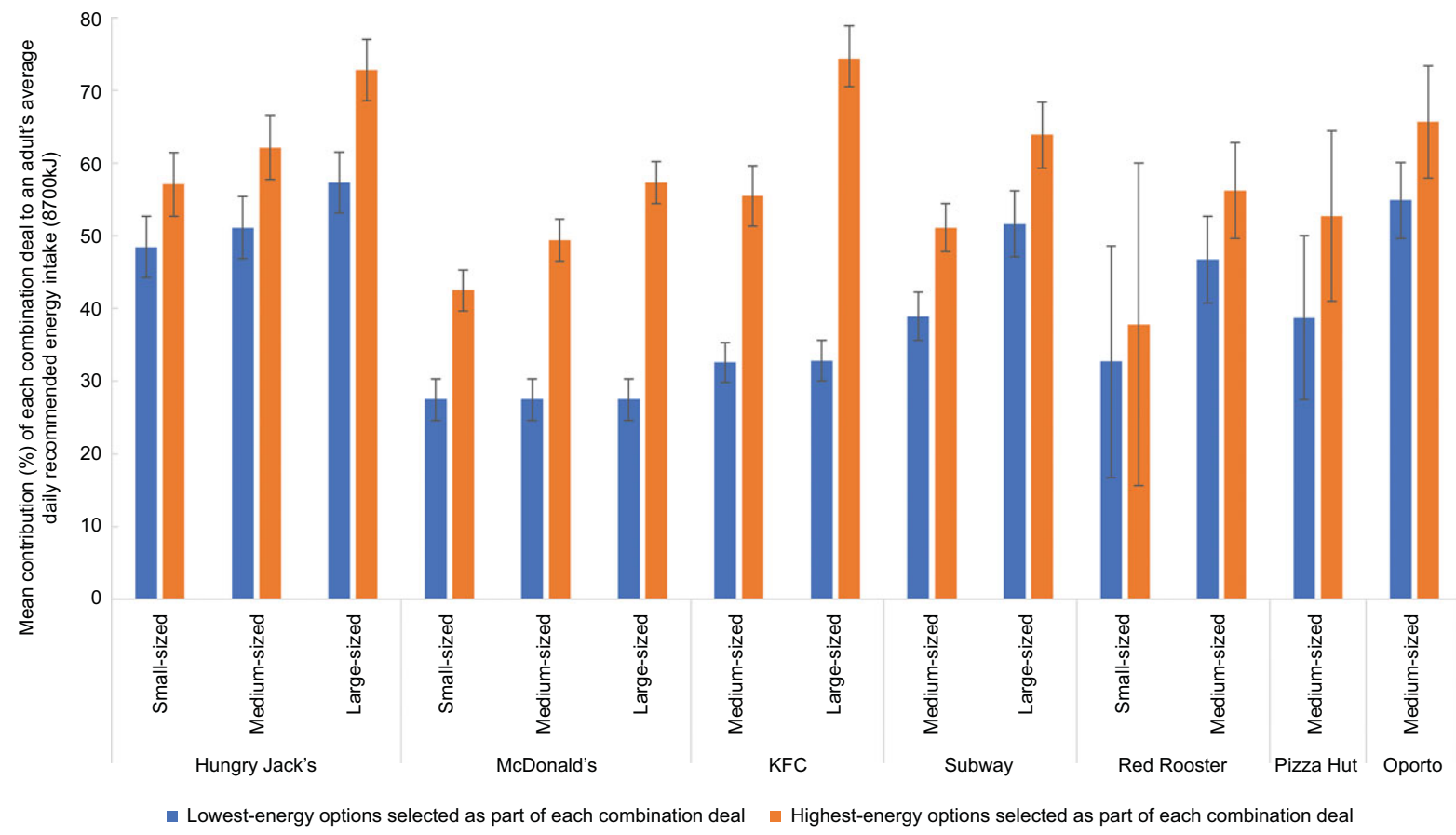

Fig. 2 (colour online) Mean percentage contribution of combination deals on 'regular menus' of selected major QSR chains in Australia to an adult's average recommended daily energy intake $(8700 \mathrm{~kJ})$, by meal size and product options selected as part of the combination deal, with $95 \% \mathrm{Cl}$ (February 2020)

lowest-energy sides, drinks and condiments were selected. However, they would be classified as 'red' if different selections were made. When the lowest-energy options were selected, McDonald's had $28.6 \%$ of their children's combination meals classified as 'amber', while Red Rooster had $25 \%$ of their combination meals classified as 'amber'.

\section{Discussion}

In this audit of ten of the largest QSR chains in Melbourne, Australia, we found extensive use of price promotions. All of the included QSR chains offered a wide range of temporary price promotions and used 'combination deals' to offer discounts to consumers if they bought multiple items at one time. QSR chains offered a discount of approximately onethird to a half off the original prices of individual food and beverage items. With regard to combination deals, the energy content, energy cost and price discount (compared to the sum of the price of the individual items) varied substantially based on the meal size and the particular sides and drinks selected. The majority of the large-sized combination deals contributed more than half of an adult's average recommended daily energy intake. All of the combination meals on regular menus were classified as 'red' (unhealthy) according to the Healthy Choices Framework.

When considering all combination deals and temporary price promotions offered by the QSR chains included in this study, our findings are in line with the findings of previous research $^{(18,27)}$ that combination deals with higher energy content sides and drinks options yielded lower energy costs. Additionally, our results indicate that individuals would consume a substantial amount of energy if sides and drink options with higher energy content (e.g. chips and sugar-sweetened drinks) were selected as part of combination deals. Most of the QSR chains had high-energy chips/fries as the only available option as part of combination deals. This finding is in line with a 2019 study $^{(35)}$ conducted in the UK that highlighted the high energy content of the sides and desserts sold in QSR chains.

In relation to children's menus, most QSR chains included in this study provided high-energy side and drink options in their children's combination deals, with substantial price savings (ranging between $21.3 \%$ and $37.5 \%$ depending on the side and drink selection) relative to stand-alone meal items. And $80.8 \%$ of combination meals on children's menus were classified as 'unhealthy'. Overall, the children's combination deals contribute between $21.7 \%$ and $34.8 \%$ of an 8-year-old child's average recommended daily energy intake of $7100 \mathrm{~kJ}$; however, this value was over $40 \%$ for the highest-energy options for a number of QSR chains. These results are similar to previous observations for Australian QSR chains ${ }^{(36)}$. The findings are also in line with a study conducted in Guatemala ${ }^{(17)}$, where the authors also found that QSR chains utilised price incentives on children's combination deals, which were all classified as 'less healthy'.

The price promotions offered on unhealthy children's meals occurred despite industry commitments to reduce 


\section{NS" Public Geath Nuerrion}

Table 5 Price savings, energy content and healthiness of combination deals available on children's menus of selected Australian QSR chains (February 2020)

\begin{tabular}{|c|c|c|c|c|c|c|c|c|c|c|c|c|c|c|c|c|c|c|}
\hline \multirow[b]{2}{*}{$\begin{array}{l}\text { QSR } \\
\text { chain* }\end{array}$} & \multirow[b]{2}{*}{$\begin{array}{l}\text { Number } \\
\text { of meals }\end{array}$} & \multicolumn{8}{|c|}{ Price saving per combination deal, relative to price of individual items } & \multicolumn{8}{|c|}{ Energy content per combination deal } & \multirow[b]{2}{*}{$\begin{array}{l}\text { Classification as per } \\
\text { Healthy Choices } \\
\text { Framework‡ }\end{array}$} \\
\hline & & $\begin{array}{c}\text { Mean } \\
\text { reduction } \\
\text { (\$) - low- } \\
\text { est-priced } \\
\text { option }\end{array}$ & $95 \% \mathrm{Cl}$ & $\begin{array}{l}\text { Mean reduc- } \\
\text { tion (\% of } \\
\text { price of indi- } \\
\text { vidual items) } \\
\text { - lowest- } \\
\text { priced option }\end{array}$ & $95 \% \mathrm{Cl}$ & $\begin{array}{l}\text { Mean } \\
\text { reduction } \\
(\$)- \\
\text { highest- } \\
\text { priced } \\
\text { option }\end{array}$ & $95 \% \mathrm{Cl}$ & $\begin{array}{l}\text { Mean reduc- } \\
\text { tion (\% of } \\
\text { price of indi- } \\
\text { vidual items) } \\
\text { - highest- } \\
\text { priced option }\end{array}$ & $95 \% \mathrm{Cl}$ & $\begin{array}{c}\text { Mean } \\
\text { energy } \\
\text { content } \\
(\mathrm{kJ})- \\
\text { lowest- } \\
\text { energy } \\
\text { option }\end{array}$ & $95 \% \mathrm{Cl}$ & $\begin{array}{l}\text { Mean contribu- } \\
\text { tion to average } \\
\text { daily recom- } \\
\text { mended energy } \\
\text { intake† - lowest- } \\
\text { energy option } \\
(\%)\end{array}$ & $95 \% \mathrm{Cl}$ & $\begin{array}{c}\text { Mean } \\
\text { energy } \\
\text { content } \\
(\mathrm{kJ})- \\
\text { highest- } \\
\text { energy } \\
\text { option }\end{array}$ & $95 \% \mathrm{Cl}$ & $\begin{array}{l}\text { Mean contribu- } \\
\text { tion to average } \\
\text { daily recom- } \\
\text { mended energy } \\
\text { intake† - high- } \\
\text { est-energy option } \\
(\%)\end{array}$ & $\begin{array}{c}95 \% \\
\mathrm{Cl}\end{array}$ & \\
\hline McDonald's & 7 & 0.75 & $-0.13,1.63$ & 9.4 & $-5 \cdot 97,24 \cdot 6$ & 5.45 & $4 \cdot 57,6 \cdot 33$ & 47.5 & $42 \cdot 5,52 \cdot 4$ & 974 & 705,1244 & 13.7 & $9 \cdot 9,17 \cdot 5$ & 3297 & 2876,3718 & 46.4 & $40 \cdot 5,52 \cdot 4$ & $\begin{array}{l}71.4 \% \text { Red, } \\
28.6 \% \text { Amber }\end{array}$ \\
\hline Grill'd & 6 & 4.50 & 0 & 26.5 & 0 & 4.50 & 0 & 26.5 & 0 & 2553 & 1070,4037 & 36.0 & $15 \cdot 1,56 \cdot 9$ & 2553 & 1070,4037 & 36.0 & $15 \cdot 1,56 \cdot 9$ & $100 \%$ Red \\
\hline $\begin{array}{l}\text { Hungry } \\
\text { Jack's }\end{array}$ & 4 & 1.26 & $0.29,2 \cdot 24$ & 17.1 & $4 \cdot 0,30 \cdot 2$ & $2 \cdot 21$ & $1 \cdot 24,3 \cdot 19$ & 26.7 & $15 \cdot 2,38 \cdot 1$ & 1214 & 725,1702 & 17.1 & $10 \cdot 2,24 \cdot 0$ & 2911 & 2422, 3399 & $41 \cdot 0$ & $34 \cdot 1,47 \cdot 9$ & $100 \%$ Red \\
\hline $\begin{array}{l}\text { Red } \\
\quad \text { Rooster }\end{array}$ & 4 & 4.24 & $-0.20,8.67$ & 40.01 & $11 \cdot 4,68.8$ & $6 \cdot 18$ & $1.74,10.61$ & $50 \cdot 0$ & $30 \cdot 2,69 \cdot 8$ & 1275 & 548,2002 & 18.0 & $7 \cdot 7,28 \cdot 2$ & 2225 & 1498,2952 & 31.3 & $21 \cdot 1,41 \cdot 6$ & $\begin{array}{l}75 \% \text { Red, } \\
25 \% \text { Amber }\end{array}$ \\
\hline Subway§ & 4 & NA & & NA & & NA & & NA & & 948 & 889,1007 & 13.4 & $12 \cdot 5,14 \cdot 2$ & 948 & 889,1007 & 13.4 & $12 \cdot 5,14 \cdot 2$ & $100 \%$ Amberf \\
\hline Oporto & 4 & 2.68 & $0.98,4.38$ & 23.49 & $12 \cdot 7,34 \cdot 3$ & 2.68 & $0.98,4.38$ & 23.5 & $12 \cdot 7,34 \cdot 3$ & 2500 & 1903,3097 & 35.2 & $26 \cdot 8,43 \cdot 6$ & 2500 & 1903,3097 & 35.2 & $26 \cdot 8,43 \cdot 6$ & $100 \%$ Red \\
\hline Nando's§ & 3 & NA & & NA & & NA & & NA & & 1337 & 597,2076 & 18.8 & $8 \cdot 4,29 \cdot 2$ & 1837 & 409, 3264 & 25.9 & $5 \cdot 8,46 \cdot 0$ & $100 \%$ Red \\
\hline KFC\| & 2 & 2.08 & $-10.31,14.46$ & $28 \cdot 15$ & $-98 \cdot 6,154 \cdot 9$ & 4.88 & $-7.51,17.26$ & 49.1 & $-15 \cdot 0,113 \cdot 3$ & 1202 & 598,1805 & 16.9 & $8 \cdot 4,25 \cdot 4$ & 2895 & 2291, 3498 & 40.8 & $32 \cdot 3,49 \cdot 3$ & $100 \%$ Red \\
\hline Total & 34 & $2 \cdot 20$ & $1 \cdot 43,2 \cdot 96$ & $21 \cdot 3$ & $14 \cdot 9,27 \cdot 8$ & $4 \cdot 26$ & $3.45,5.08$ & 37.5 & $31 \cdot 5,43 \cdot 4$ & 1538 & 1225,1851 & 217 & $17 \cdot 3,26 \cdot 1$ & 2472 & 2139,2804 & 34.8 & $30 \cdot 1,39 \cdot 50$ & $\begin{array}{l}80.8 \% \text { Red, } \\
19.8 \% \text { Amber }\end{array}$ \\
\hline
\end{tabular}

QSR, quick service restaurant; NA, not applicable.

‘Pizza Hut and Domino's did not offer any children's combination deals.

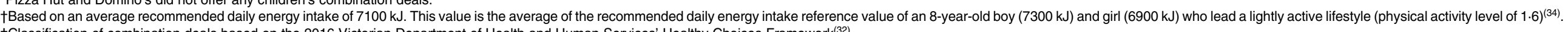
†Classification of combination deals based on the 2016 Victorian Department of Health and Human Services' Healthy Choices Framework ${ }^{(32)}$.

§These QSR chains did not offer the main meal items in the children's combination deals as individual or ala carte items; hence, the price savings could not be calculated as individual pricing for the main meal items were unavailable.

|IKFC offered a large-sized for their two children's combination deals. For this analysis, the 'large-sized' versions of these combination deals were excluded from analysis, as KFC was the only QSR chain that offered a large size.

ףWhen default side (fruit purée) and drink (bottled water) options are selected. 
marketing of unhealthy foods to children. The Australian Food and Grocery Council (AFGC) introduced a voluntary Quick Service Restaurant Initiative for Responsible Advertising and Marketing to Children (QSRI) ${ }^{(37)}$ in 2009 (updated in 2014), which set out a common framework purportedly to ensure that healthier choices were being promoted by signatory QSR chains. Six QSR chains, including McDonald's, Hungry Jack's, KFC, Oporto, Red Rooster and Pizza Hut (under the parent company, Yum! Restaurants International) signed up for the QSRI. Despite McDonald's pledge of restricting marketing and advertising to children less than 14 years old in a range of settings, as outlined in their QSRI Action Plan ${ }^{(38)}$, they offered a number of children's combination deals (referred to by McDonald's as 'Happy Meals') targeted at children below 14 years of age. Almost three-quarters $(71.4 \%)$ of McDonald's children's combination deals were classified as 'red' (unhealthy). Similarly, Oporto made a commitment regarding the energy content of their children's combination deals in their company action plan ${ }^{(39)}$ outlining that they would refrain from offering combination deals that target children between 4 and 8 years old with energy content of above $2080 \mathrm{~kJ}$ per meal. At the point that we conducted this study, we found that the lowest average energy content of children's combination deals offered by Oporto was 2500 kJ. Previous research, conducted in $2018^{(40)}$, found that Subway had a commitment to providing a healthier side and drink option as the default option in their children's combination deals. Our results indicated that they are adhering to this commitment, with all children's combination deals offered by Subway classified as 'amber' (when the default sides and drinks were selected).

\section{Implications of findings}

Price has a crucial influence on food choices ${ }^{(27,41-43)}$. The pervasiveness of price promotions and bundling incentives on energy-dense fast-food items is concerning from a public health perspective as current pricing strategies provide incentives to consume high levels of energy. Accordingly, the pricing strategies are likely to contribute to unhealthy diets and obesity. As such, routine monitoring of prices and price promotions in the fast-food sector, and their impact on consumer purchases and consumption, needs to be an important component of strategies to improve population diets and address obesity.

While some QSR chains in Australia have made some commitments to restrict marketing to children and improve the healthiness of products directed at children, these commitments are very limited and do not include price promotions. Moreover, there is consistent evidence that food industry self-regulation in regard to nutrition has largely proven to be ineffective ${ }^{(44-46)}$. As a result, governments should consider implementing policies that restrict price promotions of unhealthy fast food. While we are not aware of any governments that have taken action in relation to price promotions on fast food, recent policy announcements from the United Kingdom related to restrictions on multi-buy promotions for packaged foods high in salt, fat or sugar provide an example of the type of policies that could be implemented ${ }^{(47)}$.

For QSR chains willing to take action to address unhealthy population diets, they could consider providing healthier options (e.g. low-energy salads, grilled vegetables) as part of the combination deals they offer and making them the default option (i.e. healthier sides and drinks are automatically included as part of combination deals unless the consumer chooses a different option from a pre-specified list). For example, McDonald's could have their garden salad and water as the default side and drink options as part of its combination deals, with customers still provided a range of other options from which to choose. A switch to healthier sides and drinks as the default options echoes the recommendations provided in a recent assessment of the nutrition-related policies of major QSR chains in Australia ${ }^{(48)}$. In addition, QSR chains could adjust their pricing of combination deals to ensure that there are no pricing incentives to purchase larger sizes. This may encourage customers to choose smaller-sized meals. From a public health perspective, there is evidence that policies that change the environment in which individuals make choices, such as recipe reformulation and default healthy drinks with children's meals, tend to be more effective and equitable than interventions that rely exclusively on an individual to make healthier choices ${ }^{(49-51)}$. This is supported by the observation that, despite salads being made available for sale at McDonald's, they represented a very small proportion of sales ${ }^{(52)}$. Moreover, interventions that do not directly restrict individual choice are likely to be acceptable to a range of stakeholders ${ }^{(53)}$.

\section{Strengths and limitations}

This is the first study in Australia to comprehensively assess the temporary price promotions and pricing of combination deals offered by major QSR chains from an obesity prevention perspective. The study only examined temporary price promotions and combination deals on offer over a relatively short period (13 weeks). Our review of QSR chain websites for temporary price promotions was conducted weekly, and so it is possible that we may have missed price promotions that were only on offer for durations of shorter than a week. However, such promotions are likely to have been identified through our use of other relevant data sources (QSR chain apps and a third-party website). We classified temporary price promotions that applied to a group of menu items as a single instance of a price promotion, and so our identified number of price promotions observed can be viewed as conservative. While the study results are likely to be indicative of the types of price promotions offered by these QSR chains in Australia, future studies should examine price promotions over a longer 
period and for a broader set of QSR chains to understand variations by time of year and across different companies. Repeated studies would be valuable in understanding changes over time. While we were able to add nuance to our assessment of the energy content and healthiness of menu items by reporting a range of values for menu items that consisted of a range of sizes and options, it nevertheless proved challenging to assess and summarise the healthiness of some menu items that are highly customisable and/or designed for sharing. The highly customisable nature of QSR menu items thus needs to be taken into account when comparisons by QSR chain are made. In addition, more fine-grained tools that provide the more nuanced classification of the relative healthiness of QSR menu items may be needed, along with guidance for applying these tools in practice.

This study did not take into account price promotions that are tailored to an individual (e.g. through loyalty schemes) and/or applied on food delivery platforms (e.g. UberEats and Deliveroo) that are increasingly used for fast food $^{(54,55)}$. Future studies should explore ways to capture personalised price promotions and price promotions on food delivery platforms. Finally, this study was not designed to explore the impact of price promotions on consumer purchases and population diets. This should be the subject of future studies, including consideration of the ways in which price promotions interact with other promotional techniques and pricing strategies (e.g. range of price points, menu structure) to influence consumer choices.

\section{Conclusion}

Fast-food consumption is an important component of population diets in Australia. The current price promotion strategies adopted by major QSR chains in Australia are likely to encourage high levels of energy consumption and thereby contribute to unhealthy diets and obesity. Policies that monitor and address the strategies used by the fast-food industry to encourage consumption of unhealthy fast food need to be actively considered by governments. Specifically, policies to restrict price promotions on unhealthy foods and ensure lower-energy default items as part of combination deals should be considered as part of efforts to improve population diets and address obesity in Australia.

\section{Acknowledgements}

Acknowledgements: None. Financial support: Funding for this research was provided from the Australian Government's Medical Research Future Fund (MRFF). The MRFF provides funding to support health and medical research and innovation, with the objective of improving the health and well-being of Australians. MRFF funding has been provided to The Australian Prevention Partnership Centre under the MRFF Boosting Preventive Health Research Program. MRFF had no role in the design, analysis or writing of this article. GS, AJC and KB were supported by Heart Foundation Future Leader Fellowships (102035, 36357 and 102047, respectively) from the National Heart Foundation of Australia. GS and LGD are researchers within a National Health and Medical Research Council (NHMRC) Centre for Research Excellence entitled Reducing Salt Intake Using Food Policy Interventions (APP1117300). GS, AJC and LO are researchers within a NHMRC Centre of Research Excellence in Food Retail Environments for Health (REFRESH) (APP1152968). GS has received other funding from the NHMRC, Australian Research Council (ARC), Canadian Institutes of Health Research (CIHR) and the WHO. Conflict of interest: GS led a study to benchmark the policies and commitments of food companies (including fast-food companies) related to obesity prevention and nutrition. The other authors declare no conflicts of interest. Authorship: G.S. and K.B. conceived the study. E.S.Y.L., G.S., A.J.C. and K.B. designed the study. E.S.Y.L. conducted data collection. E.S.Y.L., G.S., A.J.C. and K.B. analysed and interpreted the data. L.O. provided advice on data analysis. E.S.Y.L., G.S. and L.G.D. drafted the manuscript, with critical input from all other authors. All authors read and approved the final version of the manuscript. Ethics of buman subject participation: No human participants were involved in this study.

\section{Supplementary material}

For supplementary material accompanying this paper visit https://doi.org/10.1017/S1368980021002688

\section{References}

1. Swinburn BA, Sacks G, Hall KD et al. (2011) The global obesity pandemic: shaped by global drivers and local environments. Lancet 378, 804-814.

2. Australian Bureau of Statistics (2016) Australian Health Survey: Consumption of Food Groups from the Australian Dietary Guidelines, 2011-12. Australia: ABS.

3. Australian Institute of Health and Welfare (2020) Overweight and Obesity among Australian Children and Adolescents. No. Cat. No. PHE 274. Canberra, Australia: Australian Institute of Health and Welfare.

4. Australian Institute of Health and Welfare (2019) Overweight \& obesity. https://www.aihw.gov.au/reports-data/behavioursrisk-factors/overweight-obesity/overview (accessed July 2020).

5. van Smeerdijk J, Jovic M, Hutchins D et al. (2015) Weighing the cost of obesity: a case for action. A study on the additional costs of obesity and benefits of intervention in Australia. Australia: PriceWaterhouse Coopers (PwC). https://www. pwc.com.au/pdf/weighing-the-cost-of-obesity-final.pdf (accessed December 2020). 
6. Lachat C, Nago E, Verstraeten R et al. (2012) Eating out of home and its association with dietary intake: a systematic review of the evidence. Obes Rev 13, 329-346.

7. Allman-Farinelli M, Rahman H, Nour M et al. (2019) The role of supportive food environments to enable healthier choices when eating meals prepared outside the home: findings from focus groups of 18 to 30-year-olds. Nutrients 11, 2217.

8. Hogan L (2018) Food Demand in Australia: Trends and Issues 2018. No. 18.10. Canberra, Australia: Australian Bureau of Agricultural and Resource Economics and Sciences (ABARES).

9. Robinson E, Jones A, Whitelock V et al. (2018) (Over)eating out at major UK restaurant chains: observational study of energy content of main meals. BMJ 363, k4982.

10. The Intermedia Group Pty Ltd (2017) Respondent Summary: Eating Out in Australia 2017. Glebe, Australia: The Intermedia Group.

11. Roy M (2018) McDonald's, KFC \& Subway most visited Aussie restaurants. http://www.roymorgan.com/findings/ 7599-australian-eating-habits-eating-in-out-march-2018-20180 5290253 (accessed July 2020).

12. Jaworowska A, Blackham T, Davies IG et al. (2013) Nutritional challenges and health implications of takeaway and fast food. Nutr Rev 71, 310-318.

13. Brindal E, Mohr P, Wilson C et al. (2008) Obesity and the effects of choice at a fast food restaurant. Obes Res Clin Pract 2, 111-117.

14. Dunford E, Webster J, Barzi F et al. (2010) Nutrient content of products served by leading Australian fast food chains. Appetite 55, 484-489.

15. Braithwaite I, Stewart AW, Hancox RJ et al. (2014) Fast-food consumption and body mass index in children and adolescents: an international cross-sectional study. BMJ Open $\mathbf{4}$, $\mathrm{e} 005813$.

16. Needham C, Orellana L, Allender S et al. (2020) Food retail environments in Greater Melbourne 2008-2016: longitudinal analysis of intra-city variation in density and healthiness of food outlets. Int J Environ Res Public Health 17, 1321.

17. Mazariegos S, Chacón V, Cole A et al. (2016) Nutritional quality and marketing strategies of fast food children's combo meals in Guatemala. BMC Obes $\mathbf{3}, 52$.

18. Basch CH, Ethan D \& Rajan S (2013) Price, promotion, and availability of nutrition information: a descriptive study of a popular fast food chain in New York City. Glob J Health Sci 5, 73 .

19. Pescud M, Friel S, Lee A et al. (2018) Extending the paradigm: a policy framework for healthy and equitable eating (HE 2). Public Health Nutr 21, 3477-3481.

20. Grier SA, Mensinger J, Huang SH et al. (2007) Fast-food marketing and children's fast-food consumption: exploring parents' influences in an ethnically diverse sample. J Public Policy Market 26, 221-235.

21. Harrington RJ, Ottenbacher MC \& Way KA (2013) QSR choice: key restaurant attributes and the roles of gender, age and dining frequency. J Qual Assur Hosp Tour 14, 81-100.

22. Nusair K, Yoon HJ, Naipaul S et al. (2010) Effect of price discount frames and levels on consumers' perceptions in lowend service industries. Int J Contemp Hosp Manag 22, 814-835.

23. Huang H-C, Chang Y-T, Yeh C-Y et al. (2014) Promote the price promotion. Int J Contemp Hosp Manag 26, 1065-1082.

24. Myung E, McCool AC \& Feinstein AH (2008) Understanding attributes affecting meal choice decisions in a bundling context. Int J Hosp Manag 27, 119-125.

25. Howes K, Shahid M, Jones A et al. (2020) Food Switch: State of the Fast Food Supply. Sydney, Australia: The George Institute for Global Health.

26. Prentice AM \& Jebb SA (2003) Fast foods, energy density and obesity: a possible mechanistic link. Obes Rev 4, 187-194.
27. Wellard L, Havill M, Hughes C et al. (2015) Energy-dense fast food products cost less: an observational study of the energy density and energy cost of Australian fast foods. Aust NZJ Public Health 39, 544-545.

28. Richards TJ \& Padilla L (2009) Promotion and fast food demand. Am J Agric Econ 91, 168-183.

29. Blattberg RC \& Neslin SA (1990) Sales Promotion: Concepts, Methods, and Strategies. Englewood Cliffs, NJ: Prentice Hall.

30. Hawkes C (2009) Sales promotions and food consumption. Nutr Rev 67, 333-342.

31. Frugal Feeds (2020) Frugal feeds. https://www.frugalfeeds. com.au/ (accessed September 2020).

32. Victorian Government (2016) Healthy choices: food and drink classification guide. DoHaH Services. Melbourne, Australia: Department of Health and Human Services.

33. State of Victoria (2020) How many kilojoules do I need each day? https://www.betterhealth.vic.gov.au/tools/energy-needskilojoules-calculator (accessed September 2020).

34. Australian National Health and Medical Research Council (2006) Dietary Energy. https://www.nrv.gov.au/node/1 (accessed September 2020).

35. Muc M, Jones A, Roberts C et al. (2019) A bit or a lot on the side? Observational study of the energy content of starters, sides and desserts in major UK restaurant chains. BMJ Open 9, e029679.

36. Wellard-Cole L, Hooper A, Watson WL et al. (2019) Nutrient composition of Australian fast-food and fast-casual children's meals available in 2016 and changes in fast-food meals between 2010 and 2016. Public Health Nutr 22, 2981-2988.

37. Australian Food \& Grocery Council (2018) Quick Service Restaurant Initiative for Responsible Advertising and Marketing to Children. Kingston, Australia: Australian Food \& Grocery Council. https://www.afgc.org.au/wpcontent/uploads/2019/06/QSR-Initiative-for-ResponsibleAdvertising-and-Marketing-to-Children-March-2018.pdf (accessed December 2020).

38. McDonald's Australia (2014) QSR Initiative for Responsible Advertising and Marketing to Children: Action Plan. https:// aana.com.au/wp-content/uploads/2020/06/QSRI_McDonalds. pdf (accessed September 2020).

39. Oporto (n.d.) Australian quick service restaurant industry initiative for responsible advertising and marketing to children: company action plan. https://aana.com.au/wpcontent/uploads/2020/06/Oporto-QSRI-Company-ActionPlan.pdf (accessed October 2020).

40. Sacks G, Robinson E, Cameron AJ et al. (2020) Benchmarking the nutrition-related policies and commitments of major food companies in Australia, 2018. Int J Environ Res Public Health 17, 6118.

41. Chandon P \& Wansink B (2011) Is food marketing making us fat? A multi-disciplinary review. Found Trends Market 5 , 113-196.

42. Andreyeva T, Long MW \& Brownell KD (2010) The impact of food prices on consumption: a systematic review of research on the price elasticity of demand for food. Am J Public Health 100, 216-222.

43. Zorbas C, Eyles H, Orellana L et al. (2020) Do purchases of price promoted and generic branded foods and beverages vary according to food category and income level? Evidence from a consumer research panel. Appetite 144, 104481.

44. Huizinga O \& Kruse M (2016) Food industry self-regulation scheme "EU Pledge" cannot prevent the marketing of unhealthy foods to children. Obes Med 1, 24-28.

45. Knai C, Petticrew M, Durand M et al. (2015) Has a publicprivate partnership resulted in action on healthier diets in England? An analysis of the Public Health Responsibility Deal food pledges. Food Policy 54, 1-10.

46. Hickey K, Mandelbaum J, Bloom K et al. (2018) Overbranded, Underprotected: How Industry Self-Regulation is Failing to 
Protect Children from Unhealthy Food Marketing. Melbourne: Obesity Policy Coalition.

47. Department of Health \& Social Care (2020) Restricting Promotions of Products High in Fat, Sugar and Salt by Location and by Price: Government Response to Public Consultation. London, UK: Department of Health and Social Care.

48. Sacks G \& Robinson E (2018) Inside our Quick Service Restaurants: Assessment of Company Policies and Commitments Related to Obesity Prevention and Nutrition. Melbourne, Australia: Deakin University. https://www. insideourfoodcompanies.com.au/quick-service-restaurants (accessed December 2020).

49. Hillier-Brown FC, Summerbell CD, Moore HJ et al. (2017) The impact of interventions to promote healthier ready-toeat meals (to eat in, to take away or to be delivered) sold by specific food outlets open to the general public: a systematic review. Obes Rev 18, 227-246.

50. Kraak V, Englund T, Misyak S et al. (2017) A novel marketing mix and choice architecture framework to nudge restaurant customers toward healthy food environments to reduce obesity in the United States. Obes Rev 18, 852-868.

51. Backholer K, Beauchamp A, Ball K et al. (2014) A framework for evaluating the impact of obesity prevention strategies on socioeconomic inequalities in weight. Am J Public Health 104, e43-e 50

52. Wellard L, Glasson C \& Chapman K (2012) Sales of healthy choices at fast food restaurants in Australia. Health Promot $J$ Aust 23, 37-41.

53. Haynes E, Hughes R \& Reidlinger DP (2017) Obesity prevention advocacy in Australia: an analysis of policy impact on autonomy. Aust N Z J Public Health 41, 299-305.

54. Bates S, Reeve B \& Trevena H (2020) A narrative review of online food delivery in Australia: challenges and opportunities for public health nutrition policy. Public Health Nutr, Jun 9, 1-11.

55. Stephens J, Miller H \& Militello L (2020) Food delivery apps and the negative health impacts for Americans. Front Nutr 7, 14 . 